\title{
Sleep Related Breathing Disorder in an Adult Female: Thinking Out of the Box G Nigam ${ }^{1}$, M Riaz $^{2}$
}

\begin{abstract}
Habitual snoring and obstructive sleep apnea (OSA) are the two most common sleep related breathing disorders. Snoring has been traditionally associated with OSA but it can occur with central sleep apnea even in absence of OSA. Any patient who demonstrates pure central sleep apnea on a baseline polysomnogram needs to undergo pertinent medical work up to establish its etiology. In this case report we discuss a case of central sleep apnea in presence of snoring, although obstructive sleep apnea was absent. We also discuss the diagnostic criteria and work up for central sleep apnea and the presence of snoring in different sleep disorders.
\end{abstract}

Keywords: Apnea hypopnea index, central sleep apnea, continuous positive airway pressure, obesity hypoventilation syndrome, obstructive sleep apnea

From: ${ }^{1}$ Clay County Hospital, 911 Stacy Burk Drive, Flora, IL 62839, USA. ${ }^{2}$ Twin Cities, Community Hospital, 1100 Las Tablas Rd, Templeton, CA 93465, USA. E-mail: hmriazmalik08@gmail.com

Correspondence: Dr G Nigam, Clay County Hospital, 911 Stacy Burk Drive, Flora, IL 62839, USA. Fax: 6186629387, e-mail: dr.nigam@claycountyhospital.org 


\section{INTRODUCTION}

Habitual snoring and obstructive sleep apnea are the two most common sleep related breathing disorders. The less common types of sleep related breathing disorders include central sleep apnea syndromes, sleep related hypoxemia and sleep related hypoventilation disorders, which can often go undetected unless in-laboratory polysomnogram with appropriate sensors are conducted. Here we present an uncommon case of sleep-disordered breathing in an otherwise fairly healthy middle-aged woman who did not have any identifiable predisposing risk factors.

\section{CASE REPORT}

A 41 year old Caucasian female with past medical history of depression and migraines presented to the sleep disorders center with complaints of snoring and excessive daytime sleepiness ongoing for about 5 years prior to presentation. Her body mass index (BMI) was $38 \mathrm{~kg} / \mathrm{m}^{2}$. She never had an echocardiogram. She denied smoking cigarettes or use of any recreational drugs. She reported consuming an occasional glass of wine on weekends but did not report drinking alcohol on the night of undergoing sleep study. Her medications included paroxetine, nortriptyline, ketorolac and naratriptan. General exam revealed an obese body habitus without kyphoscoliosis. Oral examination revealed a crowded oropharynx as suggested by Mallampati class 3 along with grade 2 tonsils. Patient underwent an in-laboratory baseline polysomnogram (PSG) to get evaluated for sleep-disordered breathing.

The details of the sleep architecture and respiratory analysis are listed in Table 1. 


\section{DISCUSSION}

The clinical history along with the polysomnographic data suggests that this patient has an uncommon yet well-defined type of sleep related breathing disorder. At first, based on clinical features (snoring, excessive daytime sleepiness, severe obesity and a crowded oropharynx) the patient seems to have a fairly high pretest probability for presence of obstructive sleep apnea (OSA). However, a closer analysis of Table 1 reveals an overall AHI of 18.8 with central apnea index of 15.6. The hypopnea index (which includes both central and obstructive hypopneas) is 3.1 and the obstructive apnea index is only 0.1 . Given the overall obstructive apnea hypopnea index is less than 5 , patient does not meet polysomnographic criteria for OSA.

With clinical history of snoring and sleepiness, polysomnographic data showing central apnea hypopnea index exceeding 5 events/hour and constituting more than $50 \%$ of the total number of respiratory events, this patient meets the criteria for central sleep apnea (CSA) syndrome (1). She did not have a Cheyne-Stokes breathing pattern associated with her CSA. She did not have have any clinical history suggestive of cardiac (such as congestive heart failure) or neurologic (such as stroke, brain neoplasm or multiple sclerosis) comorbidities that are known to be associated with CSA. Patient was not using opioid medications or benzodiazepines, which can trigger CSA. Since arterial, end-tidal or transcutaneous $\mathrm{CO} 2$ values were not measured during the sleep study it remains unknown whether patient has hypercapnic, normocapnic or hypocapnic CSA. At this time, in addition to checking awake and supine $\mathrm{PaCO} 2$ values, advanced neuroimaging to look for brain stem lesions, echocardiography to look for congestive heart failure and urine toxicology to detect drugs with respiratory depressant effects might be the additional steps needed to explore the specific etiology for her central sleep apnea. If entire 
work-up is negative, patient should be categorized as having primary or idiopathic central sleep apnea.

In most individuals, snoring is present independent of other symptoms of sleep apnea when it is called primary or simple snoring. Clinically, loud snoring has been recognized as a hallmark feature of OSA (2). So, what is the biomechanics behind generation of an audible snore? As explained by Bernoulli's pressure principle, a negative inspiratory pressure can lead to repetitive vibrations and closure of the soft palate. This in turn precipitates a turbulent airflow through the constricted pharynx that acts as a "venturi tube" leading to oscillatory vibrations of soft palate, uvula and pharyngeal walls generating an audible snore. Multiple episodes of snoring with and without associated apneic events are demonstrated in Figure 1. As can be seen in Figure 1 , snoring can be inspiratory or expiratory in nature.

Although less common in central sleep apnea syndromes, snoring has been described in patients with central sleep apnea both with and without coexisting heart failure $(3,4)$. The velopharyngeal narrowing that can occur with central apneas might explain why the snoring can be a component of CSA syndromes (5). International Classification of Sleep Disorders-3 (ICSD3) for the first time has included snoring as one of the clinical features defining central sleep apnea to highlight that snoring is not exclusively confined to patients with obstructive sleep apnea.

In conclusion, this case identified an uncommon scenario where the patient had snoring associated with idiopathic CSA but did not have OSA despite having a high clinical pretest probability for obstructive sleep apnea. Far from ruling out, snoring is one of the clinical criteria that could help establish the presence of CSA, regardless of the existence of OSA. This case undermines why clinical features alone are unreliable (and even misleading) for diagnosing 
obstructive/central sleep apnea and why a sleep study is indispensable to establish the diagnosis whenever sleep apnea is suspected. 


\section{REFERENCES}

1. ICSD-3 Online Version - American Academy of Sleep Medicine (AASM) Available at: http://www.aasmnet.org/store/product.aspx?pid=849. Accessed 3/30/2015, 2015.

2. Boynton G, Vahabzadeh A, Hammoud S, Ruzicka DL, Chervin RD. Validation of the STOP-BANG Questionnaire among Patients Referred for Suspected Obstructive Sleep Apnea. J Sleep Disord Treat Care 2013 Sep 23; 2(4):10.4172/2325-9639.1000121.

3. Javaheri S, Parker TJ, Liming JD, Corbett WS, Nishiyama H, Wexler L, et al. Sleep apnea in 81 ambulatory male patients with stable heart failure. Types and their prevalences, consequences, and presentations. Circulation 1998 Jun 2; 97(21):2154-2159.

4. Morgenthaler TI, Kagramanov V, Hanak V, Decker PA. Complex sleep apnea syndrome: is it a unique clinical syndrome? Sleep 2006 Sep; 29(9):1203-1209.

5. Badr MS, Toiber F, Skatrud JB, Dempsey J. Pharyngeal narrowing/occlusion during central sleep apnea. J Appl Physiol (1985) 1995 May; 78(5):1806-1815. 
Table 1: Baseline sleep study report

\begin{tabular}{|c|c|c|c|}
\hline \multicolumn{2}{|c|}{ Respiratory analysis parameter } & \multirow{2}{*}{$\begin{array}{l}\text { Sleep Stage } \\
\text { Stage N1 Sleep }\end{array}$} & \multirow{2}{*}{$\begin{array}{l}\begin{array}{l}\text { Percentage of } \\
\text { Total Sleep Time }\end{array} \\
5.6\end{array}$} \\
\hline $\begin{array}{l}\text { Apnea/Hypopnea } \\
\text { Index }^{\dagger}(\mathrm{AHI})\end{array}$ & 18.8 & & \\
\hline $\begin{array}{l}\text { AHI* (hypopneas } \\
\text { w/4\% } \\
\text { desaturation) }\end{array}$ & 16.3 & Stage N2 Sleep & 74.0 \\
\hline NREM AHI & 17.9 & Stage N3 Sleep & 7.3 \\
\hline REM AHI & 24.2 & Stage R Sleep & 13.1 \\
\hline $\begin{array}{l}\text { Obstructive } \\
\text { Apnea Index }\end{array}$ & 0.1 & & \\
\hline $\begin{array}{l}\text { Central Apnea } \\
\text { Index }\end{array}$ & 15.6 & $\begin{array}{l}\text { Total } \\
\text { Recording } \\
\text { Time (TRT, } \\
\mathrm{min} / \mathrm{hr} \text { ) }\end{array}$ & $478.5 / 7: 58.5$ \\
\hline $\begin{array}{l}\text { No. of central } \\
\text { apneas in REM }\end{array}$ & 6 & $\begin{array}{l}\text { Total Sleep } \\
\text { Time (TST, } \\
\text { min) }\end{array}$ & 454.0 \\
\hline $\begin{array}{l}\text { No. of central } \\
\text { apneas in NREM }\end{array}$ & 112 & $\begin{array}{l}\text { Latency to } \\
\text { sleep (min) }\end{array}$ & 6.5 \\
\hline $\begin{array}{l}\text { Hypopnea } \\
\text { Index (AASM Criteria) }\end{array}$ & 3.1 & $\begin{array}{l}\text { REM Latency } \\
\text { (min) }\end{array}$ & 182.0 \\
\hline $\begin{array}{l}\text { Mean Sleep \% } \\
\text { SpO2 }\end{array}$ & 95 & $\begin{array}{l}\text { Arousals/hour } \\
\text { of sleep }\end{array}$ & 12.0 \\
\hline Min \% SpO2 & 85 & $\begin{array}{l}\text { Sleep } \\
\text { Efficiency }\end{array}$ & $94.9 \%$ \\
\hline
\end{tabular}

$\dagger$ Index $=$ no. /hour of sleep, using AASM scoring criteria

$*$ Index $=$ no. /hour of sleep, using CMS scoring criteria min: minutes 


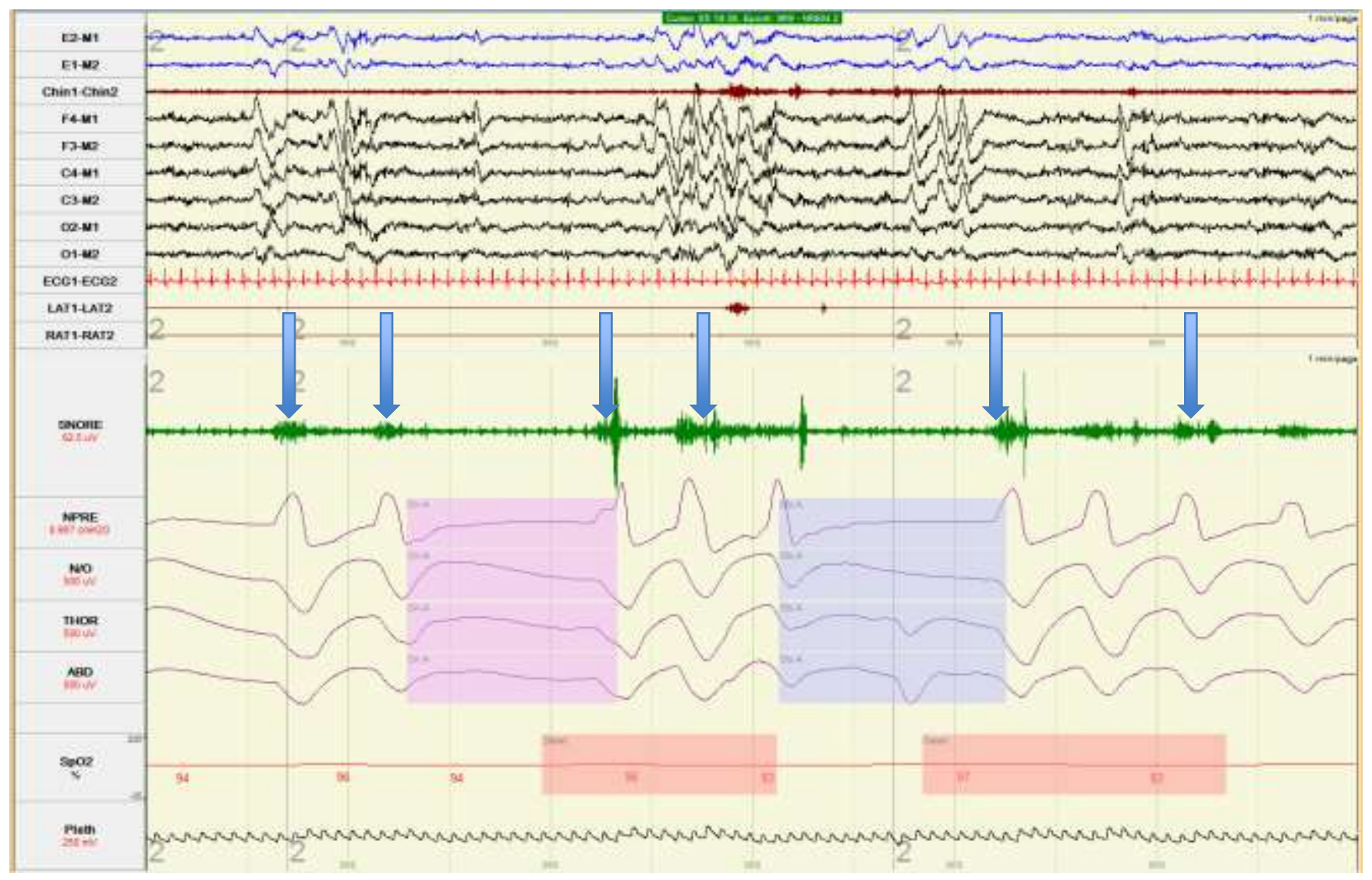

Figure: Multiple episodes of snoring (as pointed by blue arrows) are noted both preceding and following a central apnea as well as an obstructive apnea on the snore channel during stage NREM 2 on a 1 minute window.

$\mathrm{ABD}=$ abdominal excursion; $\mathrm{Cn} . \mathrm{A}=$ central apnea; Desat $=$ oxygen desaturation $(3 \%$ or more from baseline); Ob.A= Obstructive apnea; Pleth= plethysmography; $\mathrm{SpO} 2=$ oxygen saturation as measured by pulse oximetry; $\mathrm{THOR}=$ thoracic excursion. 